\title{
A nova rotina escolar e o absenteísmo-doença entre professores da Rede Municipal de Ensino de Porto Alegre (RME/POA) ${ }^{1}$
}

\author{
The new school routine and absenteeism due to sickness among Municipal Education Network of \\ teacher from Porto Alegre (MEN/POA)
}

La nouvelle routine scolaire et la maladie de l'absentéisme chez les enseignants du
Réseau Municipal de L'éducation à Porto Alegre

Caroline P. Leal

Prefeitura Municipal de Porto Alegre - PMPA²

Carla Garcia Bottega

Universidade Estadual do Rio Grande do Sul - UERGS ${ }^{3}$

\begin{abstract}
Resumo: Este estudo tem como objetivo analisar o absenteísmo-doença entre professores da Rede Municipal de Ensino de Porto Alegre (RME/POA) na série temporal de 2014-2019. Para tanto, foram investigados os afastamentos por problemas de saúde entre docentes, na busca de alterações dos indicadores analisados, desde a implantação de uma nova rotina escolar no ano de 2017. Por meio da Estatística Descritiva, fez-se uma análise quantitativa de indicadores a respeito das Licenças Tratamento de Saúde (LTS), constatando-se um significativo aumento no número delas e de docentes em LTS, bem como a redução do número de dias por licença e de dias de licença por servidor. Esses resultados nos permitem sugerir que as mudanças efetuadas na rotina escolar contribuíram para a elevação do número de afastamentos para tratamento de problemas de saúde e que os gestores necessitam promover mudanças na organização de trabalho visando à promoção de saúde dos professores.
\end{abstract}

Palavras-chave: Educação. Gestão Pública. Saúde docente.

Abstract: This study aims to analyze the absenteeism due to sickness among teachers from the Municipal Education Network in Porto Alegre (MEN/POA) from 2014 to 2019. To do so, we investigated the sick leaves among teachers searching for alterations in indicators since the implantation of a new school routine in 2017. We analyzed quantitatively the indicators of Sick Leaves (SL) using the Descriptive Statistics and discovered a significant increase in its numbers and in the number of teachers with SL. We also found a reduction in the amount of days per leave and the amount of days of each leave per employee. These results allow us to suggest that the changes concerning the school routine contributed to

\footnotetext{
${ }^{1}$ Este texto é um recorte da pesquisa realizada no curso de Especialização em Gestão Pública da Universidade Estadual do Rio Grande do Sul (UERGS) e publicada em: LEAL, Caroline P. A NOVA ROTINA ESCOLAR E A SAÚDE DOS PROFESSORES E PROFESSORAS DA REDE MUNICIPAL DE ENSINO DE PORTO ALEGRE. Monografia Universidade Estadual do Rio Grande do Sul. Curso de Especialização em Gestão Pública. Porto Alegre, 2020.

${ }^{2}$ Doutora em História pela Pontifícia Universidade Católica do Rio Grande do Sul (PUCRS). Professora da Rede Municipal de Ensino de Porto Alegre (RME/POA).E-mail: carolinep.leal@portoalegre.gov.br/.Lattes: http://lattes.cnpq.br/9940330424234005. ORCID: https://orcid.org/0000-0003-4633-8691.

${ }^{3}$ Doutora em Psicologia Social e Institucional pela Universidade Federal do Rio Grande do Sul (UFRGS). Professora Adjunta em Saúde Coletiva da Universidade Estadual do Rio Grande do Sul (UERGS). E-mail: carla-bottega@uergs.edu.br. Lattes: http://lattes.cnpq.br/4849532374275955. ORCID: https://orcid.org/0000-0001-6933-8120.
} 
elevate the number of sick leaves and that the managers need to promote changes in work organization aiming for teachers' health promotion.

Key words: Education. Public Management. Teachers health.

Résumé: Cette étude examine l'absentéisme-maladie chez les enseignants du réseau éducatif municipal de Porto Alegre (RME / POA) dans la série chronologique 2014-2019. Grâce aux Statistiques descriptives, une analyse quantitative des indicateurs a été réalisée concernant les "Licences de Traitement de Santé (LTS)" accordées aux enseignants, afin de vérifier s'il y avait un changement après la mise en place de la nouvelle routine scolaire (2017). Il y a eu une augmentation significative du nombre de LTS, ainsi que du nombre d'enseignants qui devaient entrer en LTS; le nombre de jours par congé et de jours de congé par serveur, en revanche, a diminué. Ces résultats nous permettent de suggérer que les changements apportés à la routine scolaire ont contribué à l'augmentation du nombre de congés pour se faire traiter des problèmes de santé et que les gestionnaires doivent favoriser des changements dans l'organisation du travail visant à promouvoir la santé des enseignants.

Mots clés: Éducation. Gestion publique. Enseignement de la santé.

Recebido em: 05 de julho de 2021

Aceito em: 14 de agosto de 2021

\section{Introdução}

O elevado índice de absenteísmo por motivos de saúde entre professores no Brasil tem levado a investigações sobre o surgimento às doenças causadoras dessa situação, bem como de sua relação com a natureza do trabalho. Diversas são as pesquisas - nacionais e estrangeiras -, notícias de revistas - especializadas em educação ou destinadas ao público em geral - que alertam sobre esse problema. (ESTEVE, 1999; CODO, 1999, NORONHA, 2001; ARAÚJO et al., 2003; LANTHEAUME 2007; ASSUNÇÃO et al., 2009; SCHWAILM, 201 1; TEIXEIRA, 2018).

No caso de Porto Alegre, esse panorama não é diferente. A Rede Municipal de Ensino (RME) atende em torno de 70 mil alunos e conta com cerca de 4 mil professores e 900 funcionários, sendo composta por 98 escolas: 42 (quarenta e duas) de Educação Infantil; 53 (cinquenta e três) de Ensino Fundamental; 1 (uma) de Ensino Médio; 1 (uma) de Educação Básica; o Centro Municipal de Educação dos Trabalhadores Paulo Freire e a Escola Porto Alegre (PORTO ALEGRE, 2019). Além disso, não é de hoje que afastamentos por motivo de saúde entre os professores e professoras são objetos de estudo.

Em 2014, Contiero (2014) já evidenciava esse problema. A partir de uma análise dos afastamentos para cuidados voltados à saúde dos trabalhadores da área da educação da RME, a autora constatou que os números de licenças para tratamento de saúde (LTS) na Secretaria Municipal de Educação (SMED) eram bastante elevados. Em 2012, eles representavam cerca de $34 \%$ dos afastamentos do quadro total de servidores da Prefeitura Municipal de Porto Alegre 
(PMPA). A esse respeito, dentre os motivos que levavam ao afastamento, foram apontadas as "doenças do sistema respiratório, doenças do sistema osteomuscular e tecido conjuntivo, transtornos mentais e comportamentais e fatores que influenciam a saúde”, depreendendo-se disso uma estreita relação entre a atividade laboral e o absenteísmo (CONTIERO, 2014, p. 87).

A partir do ano de 2017, com a revogação do decreto 14.521, de 2004, que regulamentava o regime normal de trabalho do magistério municipal, uma nova rotina escolar foi estabelecida na RME. Essa rotina estava pautada na alteração dos horários das escolas e de uma série de ordenamentos que organizam o cotidiano escolar, sendo o primeiro passo adotado num processo reformista, com vistas à aplicação de uma gestão por resultados na educação, da administração de Marchezan Júnior/PSDB. Ao contrário de uma gestão tradicional, focada em processos, a gestão por resultados enfatiza os objetivos a serem alcançados e os valores da organização. O foco é priorizar os resultados em todas as ações, a fim de otimizar o desempenho da organização.

[...] um marco conceitual cuja função é a de facilitar às organizações públicas a direção efetiva e integrada de seu processo de criação de valor público, a fim de otimizá-la, assegurando a máxima eficácia, eficiência e efetividade de desempenho, além da consecução dos objetivos de governo e a melhoria contínua de suas instituições (SERRA, 2008, p. 23).

Justificada pelos baixos desempenhos dos estudantes nos Índices de Desenvolvimento da Educação Básica (IDEB), a reforma educacional visava atingir os objetivos do Programa de Metas da gestão 2017-2020, como o de melhorar a qualidade do Ensino Fundamental através de algumas metas estratégicas, como podemos verificar no quadro a seguir:

Quadro 1 - Metas estratégicas da educação para atingir o objetivo estratégico de melhorar a qualidade do ensino fundamental (gestão 2017-2020)

\begin{tabular}{|c|c|}
\hline Objetivo estratégico & Meta estratégica \\
\hline \multirow{7}{*}{$\begin{array}{l}\text { Melhorar a qualidade no Ensino } \\
\text { Fundamental }\end{array}$} & META 21: Obter nota de 5,9 no IDEB 2020 - Anos Iniciais \\
\hline & META 22: Obter nota de 5,3 no IDEB 2020 - Anos Finais \\
\hline & $\begin{array}{l}\text { META 23: Assegurar que } 65 \% \text { dos alunos em anos iniciais } \\
\text { das escolas municipais sejam proficientes em português }\end{array}$ \\
\hline & $\begin{array}{l}\text { META 24: Assegurar que } 60 \% \text { dos alunos em anos iniciais } \\
\text { das escolas municipais sejam proficientes em matemática }\end{array}$ \\
\hline & $\begin{array}{l}\text { META 25: Assegurar que } 50 \% \text { dos alunos em anos finais } \\
\text { das escolas municipais sejam proficientes em português }\end{array}$ \\
\hline & $\begin{array}{l}\text { META 26: Assegurar que } 35 \% \text { dos alunos em anos finais } \\
\text { das escolas municipais sejam proficientes em matemática }\end{array}$ \\
\hline & $\begin{array}{l}\text { META 27: Garantir o acompanhamento do aprendizado a } \\
\text { cada semestre de } 100 \% \text { dos alunos da Rede Municipal } \\
\text { baseado nos descritores da Prova Brasil }\end{array}$ \\
\hline
\end{tabular}

Fonte: Prefeitura Municipal de Porto Alegre (2017). 
As novas diretrizes de organização da rede escolar foram apresentadas às direções poucos dias antes do início do ano letivo e normatizadas pela Portaria $n^{\circ} 135 / 17$. A respeito delas, as mudanças implementadas alteraram, sobretudo, os tempos escolares tempos de aprendizagem e tempos de trabalho - ao modificar os horários de entrada e de saída da escola e de duração dos períodos (de 50 para 45 minutos); ao aumentar a carga docente de atendimento direto aos alunos e alunas em sala de aula (de 15 para 17 períodos); ao deslocar as reuniões pedagógicas, os conselhos de classe e as entregas de avaliações, que eram realizadas dentro da carga horária semanal, para os sábados; e ao retirar a Hora-atividade Fora das Escola (HAFE) dos professores e professoras, obrigando-os a cumprir as horas destinadas às atividades extraclasse na escola. Tais medidas, para além de gerar uma intensificação do trabalho ${ }^{4}$, suscitaram uma profunda tensão entre a gestão municipal e o corpo docente da RME, o que nos permite questionar se a nova rotina escolar, implantada no município de Porto Alegre a partir de fevereiro de 2017 , teve efeitos sobre a saúde dos professores e professoras municipais.

Dessa forma, o presente artigo tem como objetivo analisar o absenteísmo-doença entre professores da RME/POA na série temporal de 2014-2019. Para tal, investigaremos os números relativos aos afastamentos por problemas de saúde, buscando averiguar se houve alterações dos indicadores analisados desde a implantação da nova rotina escolar.

\section{Saúde docente e reformas na educação}

O absenteísmo-doença, especificamente entre professores, não é um assunto novo na realidade brasileira, tratando-se de um fenômeno até mesmo internacional, como aponta Esteve (1999). Ele é um problema que afeta tanto o indivíduo adoecido - com efeitos sobre todas as esferas de sua vida: profissional, pessoal, espiritual e financeira - quanto a organização escolar como um todo, uma vez que interfere no cotidiano das escolas e se "reflete de forma significativa na aplicação dos conteúdos e aprendizagem dos alunos" (GONÇALVEZ; DAMLES; ZYMANSKY, 2008, p. 460).

Em vista disso, faz-se necessária uma reflexão a respeito das reformas educacionais e de seus possíveis efeitos sobre a saúde docente. Políticas em educação dependem da boa

\footnotetext{
${ }^{4}$ Por intensificação do trabalho docente entende-se o aumento de gasto de energias dos professores e professoras para a realização de suas atividades laborais, quando se passa a ser exigido um empenho maior, seja físico (corpo), intelectual (acuidade mente/saberes) ou psíquico (emocional/afetividade), ou uma combinação desses elementos, e que pode ser percebido através de fatores quantitativos, relacionados ao aumento do volume de tarefas nas escolas; e qualitativos, relacionados às circunstâncias sob as quais os docentes mobilizam as suas capacidades físicas, cognitivas e afetivas para atingir os objetivos da produção escolar (DAL ROSSO, 2008; ASSUNÇÃO; OLIVEIRA, 2009).
} 
qualidade da gestão pública, contudo, como afirma Abrucio (2016), a gestão pública precisa entender certas particularidades da educação,

do mesmo modo que a educação tem de utilizar mais a reflexão contemporânea sobre a gestão pública, a gestão pública tem de se moldar à natureza específica da educação. Médico não é igual a professor. Não quer dizer que seja melhor ou pior. A forma de trabalho é diferente (ABRUCIO, 2016, p.1)

Para conceituar gestão, levamos em conta o proposto por Gaulejac (2007), que a entende como uma tecnologia de poder que engloba um conjunto de técnicas e saberes práticos utilizados nos setores de recursos humanos de grandes empresas, visando orientar condutas e estabelecer uma cultura corporativa que mobilize as subjetividades para a realização de um ideal de indivíduo adequado às exigências da nova ordem econômica. Nesse viés, a própria gestão se torna uma ideologia que legitima a mercantilização do ser humano, transformando-o em "capital que convém tornar produtivo” (GAULEJAC, 2007, p. 28). Dessa forma, pode-se afirmar que sistemas de gestão exercem diferentes tipos de controle sobre o indivíduo e permitem que se faça um "reprocessamento da percepção do espaço produtivo", ou seja, a cada nova forma de organização do trabalho e da gestão se apresentam novas formas de manipulação da subjetividade e de exploração dos trabalhadores. (HELOANI, 2011, p. 13).

Os modelos de gestão e as mudanças efetuadas na organização do trabalho têm levado a um aumento considerável de enfermidades que estão diretamente relacionadas ao trabalho. (DEJOURS; BÈGUE, 2010; DEJOURS, 2012; HELOANI, 2013; GAULEJAC, 2007). Para Gaulejac (2011), o adoecimento e o afastamento do trabalho acabam por se tornar, muitas vezes, reações defensivas de trabalhadores a fim de suportar a violência de um sistema de gestão em que essa se torna a única maneira que esses indivíduos encontram para existir objetiva e subjetivamente.

É nesse sentido que, dentro do campo da saúde do trabalhador (perspectiva de estudo, atenção e intervenção sobre os problemas relativos à saúde dos trabalhadores), o estudo do absenteísmo tem fundamental importância. Entendido como falta não programada ao trabalho por parte de um empregado que se pensava estar presente excluindo-se os períodos de férias e de folgas - o absenteísmo tem um caráter multifatorial, apresentando como possíveis causas fatores ocupacionais, sociais, geográficos, culturais, de personalidade e de doença (OIT, 1989). Quando a causa da ausência ao serviço é doença certificada por licença médica, classifica-se essa falta como absenteísmo-doença (COUTO, 1982), que é um importante indicador das condições de saúde e de qualidade de vida dos trabalhadores. 
Em 2010, por exemplo, o relatório da Organização Mundial de Saúde (OMS), já apontava os afastamentos por licença médica como um dos maiores desafios encontrados na área de saúde do trabalhador (OPAS, 2010). Dessa forma, as constatações do aumento dos afastamentos de professores e de professoras de seu trabalho por absenteísmo-doença apontam "para a necessidade de desenvolvimento de ações referentes à reorganização do trabalho docente e promoção de saúde do professor” (CORTEZ; SOUZA; AMARAL; SILVA, 2017, p. 113).

\section{Métodos}

No presente estudo, foram analisados dados obtidos através do Portal E-sic Serviço de Informação ao Cidadão - da Prefeitura de Porto Alegre. O método de análise utilizado para tratar esses dados foi o descritivo de série temporal, com abordagem quantitativa. A população estudada, por sua vez, compreende todos os servidores da PMPA, detentores do cargo "professor".

Além disso, as recomendações do Subcomitê de Absenteísmo da Sociedade Internacional de Saúde Ocupacional (MENDES, 1980, p.56) foram utilizadas para se avaliar os indicadores (absolutos e relativos) e estabelecer graus de comparação entre elas e os dados obtidos sobre absenteísmo. Os indicadores absolutos informam os números básicos, colhidos diretamente da base de dados, no período estabelecido (20142019), com as seguintes definições:

- Número de LTS: registro de cada atestado na Perícia Médica;

- Número de professores: número de servidores detentores do cargo de "professor" na PMPA, lotados na SMED;

- Professor em LTS: número de professores em licenças para tratamento saúde.

Já os indicadores relativos comparam os dados com outros valores e apresentam as seguintes definições:

- Índice de LTS: apresenta a evolução do número de LTS ao longo do período, tomando por referência o ano de 2014 (início da série temporal pesquisada) e de 2016 (ano anterior à implantação da nova rotina escolar);

- Índice de professores: apresenta a evolução do número de professores pertencentes aos quadros da RME/POA, tendo 2014 como ano-base;

- Índice de professores em LTS: apresenta a evolução do número de professores em LTS, tendo 2014 como ano-base;

- Média de dias por LTS: soma de dias perdidos dividida pela soma de LTS; 
- Média de dias em afastamento por servidor: soma de dias perdidos dividida pela soma do número de professores em LTS;

- Taxa absenteísmo-doença: soma de dias perdidos dividida pela multiplicação do número de servidores/professores e dias de trabalho ${ }^{5}$, expresso na seguinte fórmula:

$$
\mathrm{Tad}=\frac{\text { soma de dias perdidos }}{\text { número de professores } \mathrm{x} 205}
$$

Para a análise, organização e apresentação do conjunto de dados pesquisados fizemos uso da Estatística Descritiva. De acordo com Hair Jr., Babin, Money e Samouel (2005, p. 85), muitas vezes, através da pesquisa descritiva “[...] com uso de estatísticas descritivas, o que inclui contagens de frequência (quantidade), medidas de tendência central como a média ou moda, ou uma medida de variação, como o desvio padrão" é que se consegue descrever uma situação-problema que está sendo investigada. Os valores auferidos foram organizados em tabelas e gráficos do Microsoft Excel, a fim de melhor apresentá-los e descrever as variações de maneira mais objetiva.

\section{Resultados}

Ao longo da série temporal analisada foram concedidas 38.412 LTS aos professores e professoras da RME. Em 2014, foram 5.140; em 2019, 8.550, representando um incremento de $66 \%$ no número de licenças concedidas para tratamento saúde, conforme podemos verificar na tabela que segue.

Tabela 1- LTS concedidas aos professores da RME (2014-2019)

\begin{tabular}{c|c|c|c}
\multirow{2}{*}{ Ano } & \multirow{2}{*}{$\mathbf{N}^{\mathbf{*}}$ de LTS } & \multicolumn{2}{|c}{ Índice } \\
\cline { 3 - 4 } & & Ano-base 2014 & Ano-base 2016 \\
\hline 2014 & 5140 & 100 & 98,13 \\
2015 & 5362 & 104,31 & 101,5 \\
2016 & 5283 & 102,76 & 100 \\
2017 & 5810 & 113,03 & 109,98 \\
2018 & 8276 & 161,01 & 156,65 \\
2019 & 8550 & 166,34 & 161,84 \\
\hline
\end{tabular}

Fonte: Prefeitura Municipal de Porto Alegre (2019/2020).

Se compararmos o número de licenças concedidas no primeiro ano de vigência da nova rotina escolar (2017) ao do ano anterior (2016) veremos que houve um

\footnotetext{
${ }^{5}$ Por dias de trabalho contou-se os 200 dias letivos anuais obrigatórios acrescidos de 5 dias destinados ao planejamento, avaliações e reuniões, totalizando 205 dias.
} 
acréscimo de 527 licenças, o que caracterizou um incremento de $10 \%$. Já o ano de 2018 revela uma alteração significativa: das 5.283 licenças concedidas em 2016, passou-se para 8.276 em 2018, aumentando-se em 2.993 o número de LTS. Isso representou um acréscimo de $57 \%$ nesse indicador, o que fez subir o número para $62 \%$ no ano seguinte (2019).

Há que se destacar que, dentro das normativas da nova rotina escolar para o ano de 2018, foram alteradas as diretrizes a respeito do cumprimento das horas-atividade. Somente os professores e professoras com 40 horas na mesma escola passaram a realizar 4 horas a distância (ao invés de 8 horas), enquanto os demais foram obrigados a cumprir, nas escolas, 1/3 de sua carga horária destinada ao planejamento. Além disso, ampliou-se a carga horária de trabalho, com realização de reuniões pedagógicas aos sábados (PORTO ALEGRE, 2018b).

$\mathrm{Na}$ Tabela 2 podemos verificar o número de servidores investidos no cargo de professor, lotados e em exercício na SMED, bem como o número de professores e professoras que necessitaram entrar em LTS no período correspondente à pesquisa. Percebe-se uma variação no número de professores pertencentes à RME, com tendência de queda a partir de 2017 , bem como um acréscimo de $47 \%$ no número de docentes que adoeceram entre os anos de 2014 a 2019.

Tabela 2 - Servidores investidos no cargo de professor, lotados e em exercício na SMED, e Professores em LTS (2014-2019)

\begin{tabular}{ccccc}
\hline \multirow{2}{*}{ Ano } & \multicolumn{2}{c}{ Professores SMED } & \multicolumn{2}{c}{ Professores em LTS } \\
& Número & Índice & Número & Índice \\
\hline 2014 & 3.897 & 100 & 1598 & 100 \\
2015 & 3.903 & 102,52 & 1613 & 100,93 \\
2016 & 3.910 & 100,33 & 1752 & 109,77 \\
2017 & 3859 & 99,02 & 1887 & 118,23 \\
2018 & 3538 & 90,78 & 2164 & 135,58 \\
2019 & 3692 & 94,73 & 2346 & 146,99 \\
\hline
\end{tabular}

Fonte: Prefeitura Municipal de Porto Alegre (2019/2020).

Enquanto em 2014 41\% do quadro de professores da SMED se absteve de sua atividade laboral por LTS, em 2018 esse número subiu para $61 \%$, aumentando para $63 \%$ no ano seguinte (2019). Isso representa um acréscimo de 54\% no desfalque docente dos quadros das escolas municipais por motivo de afastamento para LTS.

$\mathrm{Na}$ tabela 3, apresentamos os indicadores relativos da média de dias por licença concedida e da média de dias em afastamento por servidor, na série temporal pesquisada. 
Tabela 3 - Média de dias por licença concedida e de dias em afastamento por servidor/professor (2014-2019)

\begin{tabular}{lcrrc}
\hline Ano & $\begin{array}{c}\text { Média de dias p/ licença } \\
\text { concedida }\end{array}$ & \multicolumn{2}{c}{$\begin{array}{c}\text { Média de dias em afastamento por } \\
\text { servidor }\end{array}$} \\
\hline 2014 & 12,44 & $100 \%$ & 40,03 & $100 \%$ \\
2015 & 10,54 & $84,72 \%$ & 35,04 & $87,53 \%$ \\
2016 & 9,04 & $72,66 \%$ & 27,25 & $68,07 \%$ \\
2017 & 7,72 & $62,05 \%$ & 23,78 & $59,40 \%$ \\
2018 & 6,95 & $55,86 \%$ & 26,58 & $65,95 \%$ \\
2019 & 7,08 & $56,91 \%$ & 25,82 & $64,50 \%$ \\
\hline
\end{tabular}

Fonte: Prefeitura Municipal de Porto Alegre (2019/2020).

Observemos que há, aqui, um decréscimo nas duas variáveis apresentadas. Enquanto em 2014 um servidor ficava, em média, 40 dias afastado de seu trabalho por problemas de saúde. Porém, a partir da nova rotina escolar (2017) essa média caiu para 23 dias. Além disso, o número de dias por licença concedida teve um decréscimo de 43\% de 2014 para 2019. Apreende-se desses dados que, embora se tenha um incremento significativo de LTS, a partir do segundo ano de implantação da nova rotina escolar a duração dos afastamentos dos servidores foi reduzida em 35\%, levando-se em consideração todo o período da série temporal pesquisa (2014-2019).

De acordo Reis et al. (2006, p. 617) vários estudos têm apontado que afastamentos de curta duração podem fornecer informações a respeito do estado de saúde de determinado grupo de trabalhadores, assim como podem estar relacionados a fatores ligados à organização do trabalho, como duração da jornada, turnos e autonomia no trabalho, entre outros. Esse tipo de absenteísmo teria, então, uma "relação predominante com a organização e com os fatores de estresse no trabalho: constrangimentos pessoais, tensão organizacional, limitações na carreira e sobrecarga de trabalho”.

Já os afastamentos de longa duração têm uma relação direta com o adoecimento propriamente dito (PRIMO; PINHEIRO; SAKURAI, 2010). Também, de acordo com Ybema, Smulders e Bonger (2010), frequentes faltas podem significar que um trabalhador precisa de tempo para se recuperar das tensões no trabalho, e a ausência prolongada pode ser um indicador de problemas mais graves. O que nossos dados indicam, portanto, é que o adoecimento docente, sobretudo a partir do segundo ano de implantação da nova rotina escolar, parece estar calcado mais em fatores relacionados às tensões estabelecidas no ambiente, como indicado pelos autores supramencionados. A esse respeito, em 2019, por exemplo, $57 \%$ das LTS concedidas aos professores e professoras municipais foram de até 3(três) dias de afastamento (PORTO ALEGRE, 2020).

O absenteísmo no trabalho é um dos indicadores mais utilizados pela gestão de recursos humanos das organizações. Segundo Chiavenato (2009), o índice de absenteísmo 
deve refletir a porcentagem do tempo não trabalhado em decorrência das ausências com relação ao volume de atividade esperada ou planejada. Dessa forma, o absenteísmo-doença além de ser um indicador das condições de saúde e de qualidade de vida dos trabalhadores, tem grande impacto nas organizações, uma vez que interfere na produção, aumentando o custo operacional e reduzindo a eficiência no trabalho.

No caso dos professores, o impacto direto se dá na aprendizagem dos estudantes. De acordo com Costa (2017, p. 16), o absenteísmo docente é apontado em alguns estudos como um dos responsáveis pela baixa qualidade da educação brasileira quando medida, por exemplo, pelo desempenho dos alunos em testes de proficiência como o PISA - Programa Internacional de Avaliação dos Estudantes. A partir disso, no gráfico a seguir, apresentamos o indicador “Taxa absenteísmo-doença (Tad)” entre professores RME/POA relativos aos anos de 2014 e 2019.

Gráfico 1 - Taxa Absenteísmo Doença entre professores da RME/POA (2014-2019)

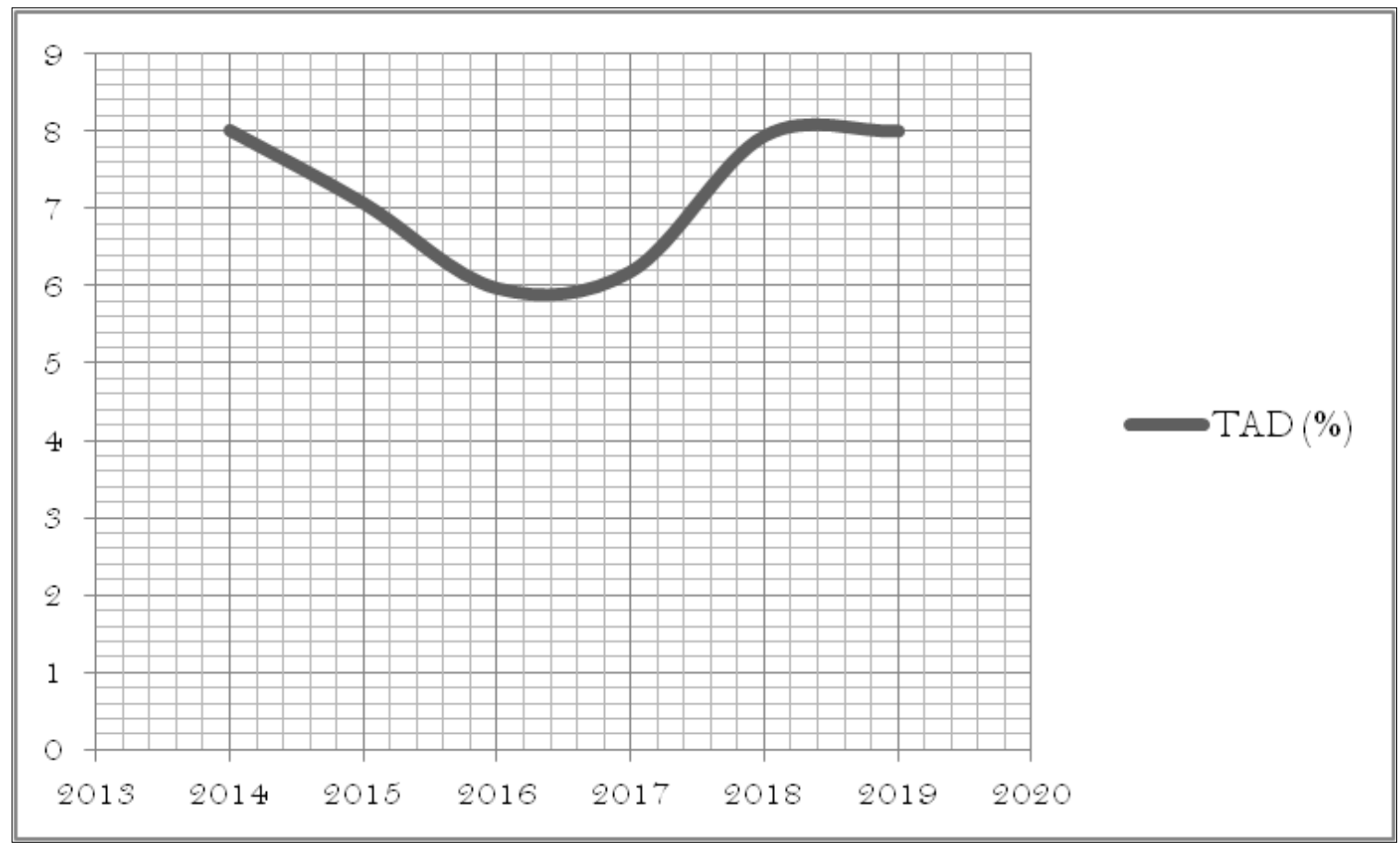

Fonte: Prefeitura Municipal de Porto Alegre (2019/2020).

Podemos perceber, ainda, que ao longo do período pesquisado, a Taxa absenteísmo-doença entre professores da RME/POA sofreu uma significativa oscilação. A partir de 2014, esse indicador vinha em uma função decrescente, atingindo seu menor valor no ano de 2016; era 8\% e chegou a 5, 96\%. A partir de 2017, contudo, a Tad voltou a crescer, registrando 6,18\% no referido ano; 7,93\%, em 2018; 7,99\%, em 2019 e atingindo os valores iniciais da série temporal pesquisada. Além de indicar problemas 
nas condições de saúde e de qualidade de vida docente, a regressão na melhoria do indicador, a partir de 2017, sinaliza possíveis prejuízos aos resultados pretendidos pela organização ao afetar o desempenho organizacional.

\title{
Discussão
}

A partir dos dados analisados, identificamos um elevado índice de LTS entre professores do município de Porto Alegre, sobretudo a partir do ano de 2018. Esse acréscimo coincidiu com a retirada da possibilidade de os professores e professoras realizarem suas atividades de estudo, de planejamento, de correção fora da escola com a ampliação de sua carga horária e a realização de reuniões pedagógicas aos sábados. Verificamos, na série temporal 2014-2019, que houve um acréscimo de 66\% no número de LTS concedidas e que, no ano de 2019, 63\% do quadro docente da SMED se absteve de suas atividades por motivo de doença.

Em artigo que reflete sobre as relações entre o processo de trabalho docente, as reais condições sob as quais ele se desenvolve e o possível adoecimento físico e mental dos professores, Assunção, Barreto e Gasparini (2005, p. 191) questionam "quais seriam os efeitos para o professor, se, no espaço da produção do ensino, não lhe são garantidas as condições adequadas para atingir as metas que orientam as reformas educacionais recentes?” De acordo com as autoras,

\begin{abstract}
[...] as condições de trabalho, ou seja, as circunstâncias sob as quais os docentes mobilizam as suas capacidades físicas, cognitivas e afetivas para atingir os objetivos da produção escolar podem gerar esforço ou hipersolicitação de suas funções psicofisiológicas. Se não há tempo para a recuperação, são desencadeados ou precipitados os sintomas clínicos que explicariam os índices de afastamento do trabalho por transtornos mentais. (ASSUNÇÃO; BARRETO; GASPARINI, 2005, p.192).
\end{abstract}

Do mesmo modo, Esteve (1999, p. 57) apresenta as condições de trabalho - que agem indiretamente sobre a imagem do professor - como fatores secundários que levariam ao fenômeno do "mal-estar docente", resultando no "ciclo degenerativo da eficácia docente”. A partir disso, nos questionamos em que medida a supressão da horaatividade fora da escola pode ter contribuído para um significativo aumento das licenças para tratamento saúde dos professores, haja vista a inadequação dos espaços de trabalho e a mudança proposta pela nova rotina escolar ${ }^{6}$.

\footnotetext{
${ }^{6}$ Em abril de 2018, o mandato do vereador Prof. Alex Fraga publicou um Relatório sobre as condições precárias das Escolas Municipais de Porto Alegre, fruto de visitas realizadas entre março e abril do referido ano a todas "as 56 escolas de ensino fundamental e médio da rede municipal de Porto Alegre para falar com direções e professores sobre as condições de trabalho e a estrutura física dos espaços” (FRAGA, 2018, p. 2). O documento aponta para uma "precarização do ensino e das relações de trabalho na rede municipal" (FRAGA, 2018, p. 34), destacando a falta de condições adequadas para que os docentes realizem suas atividades laborais.
} 
Além da precariedade do ambiente, para que sejam realizadas as atividades extraclasse na escola, ao retirar-se a HAFE também se negou aos professores e professoras um momento em que podiam se ausentar do ambiente escolar, permitindo um tempo para a recuperação de suas capacidades psicofisiológicas, sem a necessidade de afastamento médico. É nesse sentido que, para Esteve (1999), o absenteísmo seria um mecanismo de defesa utilizado contra a tensão derivada do exercício docente, uma forma de atingir um alívio para escapar das tensões acumuladas. Segundo Dejours (1999), não há passividade ou neutralidade nos efeitos da organização do trabalho, pois as pessoas se defendem e constroem estratégias específicas e, por essa razão, podem não adoecer.

Hipersolicitados em função da sobrecarga de trabalho intensificada a partir da nova rotina escolar e com a perda da HAFE, o professor deixa de dispor desse tempo para a sua recuperação física e mental, o que desencadeia sintomas clínicos que ajudam a explicar os altos índices de afastamento do trabalho por LTS entre professores da RME/POA. Ademais, observamos que houve um decréscimo na média de dias por LTS e de dias em afastamento por servidor. Ou seja, embora se tenha um incremento significativo de licenças concedidas a partir da nova rotina escolar, esses afastamentos tiveram sua duração reduzida. Isso também nos permite relacionar esses adoecimentos a fatores vinculados à organização, como sobrecarga e condições de trabalho, entre outros.

Outra constatação importante diz respeito à eficiência do trabalho docente. Ao analisarmos a taxa absenteísmo-doença, identificamos que, a partir da nova rotina escolar, houve uma regressão na melhoria que vinha ocorrendo nesse indicador. Ao afetar seu desempenho, o aumento do indicador pode ter causado prejuízo aos resultados a serem atingidos pela organização. Há de se destacar que, a fim de atingir o objetivo de melhorar a qualidade do Ensino Fundamental, uma das metas estratégicas estabelecidas pela gestão 2017-2020 era aumentar o desempenho dos alunos e alunas no IDEB. Nos Anos Iniciais a meta era obter nota de 5,9 no IDEB 2020; mas obteve 4,9. Já nos Anos Finais, não só não foi alcançada a meta de 5,3 no IDEB 2020, que ficou 1,6 pontos abaixo do projetado, como se regrediu 0,1 ponto, quando comparado ao IDEB 2015 (PROMETA, 2017; INEP, 2020).

A gestão por resultados tem como objetivo a criação de valor público ao se atingir os resultados estipulados nos objetivos dos programas de governo. Nesse sentido, a existência de prejuízos no que tange à saúde dos professores e professoras, e com o aumento do número de afastamentos por LTS, observa-se que a nova rotina escolar parece ter dificultado o alcance das metas definidas pelo próprio plano de gestão 2017-2020, que era o de melhorar a qualidade do Ensino Fundamental. Ainda, o aumento do número de afastamentos por licença saúde entre docentes, e o número de 
professores e professoras que necessitaram se afastar do trabalho por motivo de saúde, ampliaram-se os obstáculos para a obtenção dos resultados estipulados pela organização, o que não se traduziu em efetividade de desempenho.

\section{Considerações finais}

Mesmo que se verifique o crescimento do adoecimento docente no trabalho, de acordo com Cortez, Souza, Amaral e Silva (2017, p. 113), “poucas ações são desenvolvidas em relação às legislações e políticas específicas que privilegiam a saúde do professor, apesar do elevado número de estudos ressaltando agravos à saúde docente”. Assim, essa forma de absenteísmo tem se tornado prevalente, como um problema que tende ao agravamento, principalmente por ainda ser pouco discutido na administração pública e necessitar de levantamentos e pesquisas que constituam dados para a criação de uma política de saúde pública efetiva para esse grupo de trabalhadores.

Embora, neste estudo, não tenhamos elementos sobre quais situações de saúde levaram ao afastamento dos professores e professoras de suas atividades laborais, a partir dos dados analisados e da bibliografia existente sobre o tema indicamos que o aumento significativo das LTS dos docentes da RME, bem como o número dos que necessitaram entrar em LTS, sobretudo a partir de 2018, sugerem que eles estão relacionados a determinantes organizacionais do trabalho e à inadequação dos instrumentos e das normativas estabelecidas pela nova rotina escolar.

Dispor dessas informações alicerça a proposição de planos de ação viáveis, que promovem o reexame de modelos gerenciais e dos instrumentos adotados por esse modelo de gestão em prol da reorganização do trabalho docente e da promoção de saúde de professores e professoras da RME/POA. Dessa forma, realizar o diagnóstico da situação de saúde/doença entre professores permite a instrumentalização dos gestores na aplicação de uma política de saúde do trabalhador que promova mudanças na organização de trabalho e diminua o número de adoecidos.

\section{Referências}

ABRUCIO, F. Gestão Pública precisa entender as particularidades da educação. Revista Educação, v. 234, nov. 2016. Disponível em: http://www.revistaeducacao.com.br/gestaopublica-precisa-entender-particularidades-da-educacao/. Acesso em: 6 fev. 2019.

ARAÚJO, J. Afastamento do trabalho: absenteísmo e presenteísmo em uma instituição federal de Ensino Superior. 123f. Dissertação (Mestrado em Ciência da Saúde) Universidade de Brasília, Brasília, 2012. Disponível em: https://doi.org/10.5327/z16794435201917s1tlo98. Acesso em: 30 mar. 2020. 
ARAÚJO, T. M. et al. Saúde e trabalho docente: dando visibilidade aos processos de desgaste e adoecimento docente a partir da construção de uma rede de produção coletiva. Educação em Revista, Belo Horizonte, v. 37, p. 183-212, 2003.

ASSUNÇÃO, A.; BARRETO, S.; GASPARINI, S. O professor, as condições de trabalho e os efeitos sobre sua saúde. Educação e Pesquisa, São Paulo, v. 31, n. 2, p. 189-199, maio/ago. 2005. Disponível em: https://doi.org/10.1590/s1517-97022005000200003. Acesso em: 6 fev. 2019.

ASSUNÇÃO, A.; OLIVEIRA, D. Intensificação do trabalho e a saúde dos professores. Educ. Soc., Campinas, v. 30, n. 107, p. 349-372, maio/ago. 2009. Disponível em: https://doi.org/10.1590/s0101-73302009000200003. Acesso em: 6 fev. 2019.

CHIAVENATO, I. Recursos Humanos: o capital humano das organizações. Rio de Janeiro: Elsevier, 2009.

CODO, W. Educação, carinho e trabalho. Petrópolis: Vozes, 1999.

CONTIERO, P. Análise dos Afastamentos Para Tratamento de Saúde dos Trabalhadores em Educação da Rede Municipal de Ensino de Porto Alegre. $115 f$. Monografia (Graduação em Administração) - Universidade Federal do Rio Grande do Sul, Porto Alegre, 2014. Disponível em: https://doi.org/10.29289/259453942018v28s 1059. Acesso em: 12 fev. 2020.

CORTEZ, P. A.; SOUZA, M. V. R.; AMARAL, L. O.; Silva, L. C. A. A saúde docente no trabalho: apontamentos a partir da literatura recente. Cad. Saúde Colet., Rio de Janeiro, v. 25, n. 1, p. 113-122, 2017. Disponível em: https://doi.org/10.1590/1414-62x201700010001. Acesso em: 15 mar. 2020.

COSTA, R. A. Absenteísmo por doenças em docentes do Ensino Fundamental. 80f. Dissertação (Mestrado Profissional em Gestão de Organização da Saúde) - Universidade de São Paulo, Ribeirão Preto, 2017. Disponível em: https://doi.org/10.29381/01038559/20203002248-56. Acesso em: 15 mar. 2020.

COUTO, H. A. Absenteísmo: uma visão maior que a simples doença. Ergo, Belo Horizonte, n. 2 , jul. 1982 .

DAL ROSSO, S. Mais Trabalho! A intensidade do labor na sociedade contemporânea. São Paulo: Boitempo, 2008.

DEJOURS, C. Conferências brasileiras: identidade, reconhecimento e transgressão no trabalho. São Paulo: Fundap, 1999.

DEJOURS, C. Trabalho vivo: sexualidade e trabalho - tomo I. Brasília: Paralelo 15, 2012.

DEJOURS, C.; BÈGUE, F. Suicídio e trabalho: o que fazer? Brasília: Paralelo 15, 2010.

ESTEVE, J. M. Mal-estar docente: a sala de aula e a saúde do professor. Bauru: EDUSC, 1999.

FRAGA, A. Relatório sobre as condições precárias das Escolas Municipais de Porto Alegre. Porto Alegre: Câmara Municipal de Porto Alegre, 2018. Disponível em: https://doi.org/10.47749/t/unicamp.2004.324676. Acesso em: 30 mar. 2020. 
GAULEJAC, V. A NGP: a nova gestão paradoxal. In: BENDASSOLLI, P. F.; SOBOLL, L. A. P. (org.). Clínicas do trabalho: novas perspectivas para compreensão do trabalho na atualidade. São Paulo. Atlas, 2011. Disponível em: https://doi.org/10.1590/s141565552013000100009. Acesso em: 30 mar. 2020.

GAULEJAC, V. Gestão como doença social: ideologia, poder gerencialista e fragmentação social. São Paulo: Ideias \& Letras, 2007. Disponível em: https://doi.org/10.1590/s030376572012000200010. Acesso em: 30 mar. 2020.

GONÇALVEZ, J. P.; DAMLE, M. P.; SZYMANSKY, M. L. O mal-estar docente segundo a percepção de coordenadores pedagógicos da rede pública de Cascavel. In: Congresso Nacional de Educação, 8, 2008, Curitiba. Anais […]. Curitiba: PUC, p. 4597-4606, 2008.

HAIR JR., J. F.; BABIN, B.; MONEY, A. H.; SAMOUEL, P. Fundamentos de métodos de pesquisa em administração. Porto Alegre: Bookman, 2005.

HALMENSCHLAGER, B. Análise Estatística dos Afastamentos dos Professores da Rede Municipal de Ensino de Porto Alegre. 54f. Monografia (Graduação em Estatística) Universidade Federal do Rio Grande do Sul, Porto Alegre, 2018. Disponível em: https://doi.org/10.29289/259453942018v28s1059. Acesso em: 30 mar. 2020.

HELOANI, R. Organização do trabalho e administração: uma visão multidisciplinar. São Paulo: Cortez, 2011.

INSTITUTO NACIONAL DE ESTUDOS E PESQUISAS EDUCACIONAIS ANÍSIO TEIXEIRA - INEP. Índice de Desenvolvimento da Educação Básica (IDEB). INEP, 2020. Disponível em: https://doi.org/10.24109/9788578630652.ceppe. Acesso em: 16 set. 2020.

LANTHEAUME, F. Mal-estar docente ou crise do ofício?: quando o "belo trabalho" desaparece e é preciso "trabalhar de corpo e alma”. Fórum Sociológico, Lisboa, n. 15-16, p. 141-156, 2007.

LEAL, C. P. A nova rotina escolar e a saúde dos professores e professoras da rede municipal de ensino de Porto Alegre. 61f. Monografia (Especialização em Gestão Pública) - Universidade Estadual do Rio Grande do Sul, Porto Alegre, 2020. Disponível em:

https://repositorio.uergs.edu.br/xmlui/bitstream/handle/123456789/984/27119_tcc_carol ine pereira leal gestaao paublica.pdf? sequence $=-1$ \&isAllowed=y. Acesso em: 30 mar. 2020.

MENDES, R. Medicina do Trabalho e doenças profissionais. São Paulo: Savier, 1980.

NORONHA, M.M.B. Condições do exercício profissional da professora e dos possíveis efeitos sobre a saúde: estudo de casos das professoras do Ensino Fundamental em uma escola pública de Montes Claros, Minas Gerais. Dissertação (Mestrado em Saúde Pública) Universidade Federal de Minas Gerais, Belo Horizonte, 2001.

ORGANIZAÇÃO INTERNACIONAL DO TRABAHO - OIT. Absentismo: causa y control. In: ORGANIZAÇÃO INTERNACIONAL DO TRABAHO - OIT. Enciclopedia de salud e seguridad en el trabajo. Madri: OIT, 1989. P. 5-12.

ORGANIZAÇÃO PAN-AMERICANA DA SAÚDE - OPAS. Saúde e ambiente: saúde do trabalhador. Brasília: OPAS, 2010. Disponível em: https://doi.org/10.1590/s0103-

11042013000100004. Acesso em: 15 mar. 2020. 
PORTO ALEGRE. Programa de Metas 2017-2020. Prefeitura Municipal de Porto Alegre, 2017. Disponível em:

http://lproweb.procempa.com.br/pmpa/prefpoa/smpeo/usu_doc/prometa_poa_20172020.pdf. Acesso em: 30 mar. 2020.

PORTO ALEGRE. Secretaria municipal de Educação. Portaria 024/2018. Prefeitura Municipal de Porto Alegre, 2018. Disponível em:

http://www2.portoalegre.rs.gov.br/netahtml/sirel/atos/Portaria\%20024\%202018\%20SME D\%20retificada. Acesso em: 1 jan. 2020.

PORTO ALEGRE. Secretaria Municipal da Educação. Prefeitura Municipal de Porto Alegre, 2019. Disponível em: https://prefeitura.poa.br/smed. Acesso em: 29 dez. 2019.

PORTO ALEGRE. Secretaria Municipal de Planejamento e Gestão. LTS professores (2019). Prefeitura Municipal de Porto Alegre, 2020.

PRIMO, G.; PINHEIRO, T.; SAKURAI, E. Absenteísmo por doença em trabalhadores de uma organização hospitalar pública e universitária. Rev Med Minas Gerais, Belo Horizonte, v. 20, p. 47-58, abr./jun., 2010.

REIS, R., et al. Absenteísmo, doença e enfermagem. Revista de Saúde Pública, São Paulo, v. 27, n. 5, p. 616-623, 2003.

SANTANA, F.; NEVES, I. Saúde do trabalhador em educação: a gestão da saúde de professores de escolas públicas brasileiras. Saúde Soc., São Paulo, v. 26, n. 3, p. 786-797, 2017. Disponível em: https://doi.org/10.1590/s0104-12902017167259. Acesso em: 15 mar. 2020.

SCHWAILM, P. H. Saúde docente: possibilidades e limites. PDE - Gestão Escolar. Brasília: DF, 2019. Disponível em: http://www.gestaoescolar.diaadia.pr.gov.br/. Acesso em: 25 jul. 2019.

SERRA, A. Modelo aberto de gestão de resultados no setor público. Natal: SEARH, 2008.

YBEMA, J.; SMULDERS, P.; BONGERS, P. Antecedents and consequences of employee absenteeism: longitudinal perspective on the role of job satisfaction and burnout. European Journal of Work and Organizational Psychology, Bruxelas, v. 19, n.1, p. 102-24, 2010. Disponível em: https://doi.org/10.1080/13594320902793691. Acesso em: 15 mar. 2020. 